\title{
An Alternative Method for Determining the Radiochemical Purity of ${ }^{99 m}$ Tc-Tetrofosmin
}

Kanak C. Amin, Sagar Patel, Aniruddha Doke, and Gopal B. Saha

Department of Nuclear Medicine (Jb-3), Cleveland Clinic Foundation, Cleveland, Ohio

The instant thin-layer chromatographic method of determining the radiochemical purity of $99 \mathrm{~m} T \mathrm{~T}$-tetrofosmin recommended by the manufacturer uses a mixture of acetone and dichloromethane (35:65 v/v) as the solvent and a silica gel (SG) strip as the solid phase. Currently, SG strips are not available commercially and an alternative solid phase is needed. The present study reports that silicic acid strips are an appropriate substitute for SG strips for the chromatographic method using the same solvent mixture but mixed in a reverse ratio $(65: 35 \mathrm{v} / \mathrm{v})$. The 2 methods yielded similar values (within $1 \mathrm{SD}$ ) of radiochemical purity for ${ }^{99 m}$ Tc-tetrofosmin.

Key Words: radiochemical purity; thin-layer chromatography; 99mTc-tetrofosmin

J Nucl Med Technol 2011; 39:51-54

DOI: 10.2967/jnmt.110.080788

$\mathbf{R}$ adiopharmaceuticals for human use must undergo strict quality control measures to ensure patient safety. The tests include radionuclidic purity, $\mathrm{pH}$, ionic strength, chemical purity, and radiochemical purity. For daily ${ }^{99 \mathrm{~m}} \mathrm{Tc}$ kit preparations, all tests except radiochemical purity can be accomplished well before the time of reconstitution. These kits are reconstituted daily by the addition of ${ }^{99 \mathrm{~m}} \mathrm{Tc}$-pertechnetate to the kit vial containing a reducing agent such as stannous ion and chelating agents such as diethylenetriaminepentaacetic acid, methylene diphosphonate, and so on. ${ }^{99} \mathrm{~m} \mathrm{Tc}^{7+}$ is reduced to lower oxidation states by stannous ion $\left(\mathrm{Sn}^{2+}\right)$, and the reduced ${ }^{99 \mathrm{~m}} \mathrm{Tc}$ then binds to the chelating agent to give ${ }^{99 \mathrm{~m}} \mathrm{Tc}$ complex. Incomplete reduction and partial binding can lead to the presence of free and reduced ${ }^{99 \mathrm{~m}} \mathrm{Tc}$ along with ${ }^{99 \mathrm{~m}} \mathrm{Tc}$ complex in the preparation. In water, the reduced ${ }^{99 \mathrm{~m}} \mathrm{Tc}$ is hydrolyzed to

Received Aug. 2, 2010; revision accepted Oct. 1, 2010.

For correspondence or reprints contact: Gopal B. Saha, Department of Nuclear Medicine (Jb-3), Cleveland Clinic Foundation, 9500 Euclid Ave., Cleveland, $\mathrm{OH} 44195$.

E-mail: gbsaha@gmail.com

COPYRIGHT @ 2011 by the Society of Nuclear Medicine, Inc. several species whose composition is not definitely known. In daily preparations of these radiopharmaceuticals, the proportions of these entities can vary and must be determined before administration to patients because the free and hydrolyzed ${ }^{99 \mathrm{~m}} \mathrm{Tc}$ obscures the scintigraphic images and exposes the patient to unnecessary radiation. Instant thin-layer chromatography (ITLC) is a quick method of assessing the radiochemical purity of the ${ }^{99 \mathrm{~m}} \mathrm{Tc}$ complex and uses a solvent and a solid phase to separate the different components. One can then measure the activity of each component, from which the fractions of free, hydrolyzed, and chelated (bound) ${ }^{99 \mathrm{~m}} \mathrm{Tc}$ in the preparation are determined.

The ITLC procedure recommended by the manufacturer (GE Healthcare) for ${ }^{99 \mathrm{~m}} \mathrm{Tc}$-tetrofosmin (Myoview) requires a solvent of a mixture of acetone and dichloromethane (35:65 $\mathrm{v} / \mathrm{v}$ ) and a solid phase of a silica gel (SG) strip (1). Currently, SG strips have been discontinued by the manufacturer and are not available commercially. Also, the method has the disadvantage of a long procedural time and requires experience with the procedure. Two alternative methods have been reported to mitigate the situation. McKay et al. (2) performed the chromatography using Whatman 1 strips and ethyl acetate and obtained radiochemical purity similar to the manufacturer's recommended values. Eggert et al. (3) reported radiochemical purity in agreement with that of the recommended method, using a solvent-saturated pad and a 1:1 chloroform:tetrahydrofuran solvent mixture.

Although these methods are reasonable enough for daily determination of the radiochemical purity of ${ }^{99 \mathrm{~m} T c}$-tetrofosmin, in the absence of SG strips we felt the urgency of having an alternative method. After trials with several alternative solid phases and solvents, we found that the silicic acid (SA) strip is an appropriate alternative to the SG strip for ITLC of ${ }^{99 \mathrm{~m} T c-t e t r o f o s m i n}$ using a solvent mixture of acetone and dichloromethane $(65: 35 \mathrm{v} / \mathrm{v}$, a reverse ratio of the manufacturer's method). The following is a brief description of the method and the results of ITLC separation of the 3 components-free, hydrolyzed, and bound ${ }^{99 \mathrm{~m}} \mathrm{Tc}$-in the ${ }^{99 \mathrm{~m}} \mathrm{Tc}$-tetrofosmin sample.

\section{MATERIALS AND METHODS}

After experiments with several solid phases (Whatman 1 and 3 strips) and solvents (acetone, saline, ethyl acetate, 35:65 acetone:dichloromethane) for an appropri- 
TABLE 1

Material Data for the Chromatographic Method

\begin{tabular}{ccc}
\hline Parameter & $\begin{array}{c}\text { Manufacturer's } \\
\text { method }\end{array}$ & $\begin{array}{c}\text { Alternative } \\
\text { method }\end{array}$ \\
\hline $\begin{array}{c}\text { Chromatography } \\
\text { strip }\end{array}$ & $\mathrm{SG}$ & $\mathrm{SA}$ \\
Solvent & $35 \%$ acetone & $65 \%$ acetone \\
& $65 \%$ & $35 \%$ \\
Strip size & $2 \times 20 \mathrm{~cm}$ & $\begin{array}{c}\text { dichloromethane } \\
1.5 \times 11 \mathrm{~cm}\end{array}$ \\
\hline
\end{tabular}

ate chromatographic method to determine the radiochemical purity of ${ }^{99 \mathrm{~m}} \mathrm{Tc}$-tetrofosmin, we found an optimal method using a mixture of 65:35 acetone:dichloromethane $(\mathrm{v} / \mathrm{v})$ as the solvent and an SA strip as the solid phase (Table 1).

The required materials are a mixture of acetone and dichloromethane $(65: 35 \mathrm{v} / \mathrm{v})$, an approximately 10-cm-long cylindric glass vial of diameter of $2.5 \mathrm{~cm}$, an ITLC SA strip $(11 \times 1.5 \mathrm{~cm})$, a $1-\mathrm{mL}$ syringe with 25 -gauge needle, and a dose calibrator or any suitable counting system. The ratio of solvents in the mixture is in reverse proportion to the ratio used by the manufacturer. The SA strips are commercially available in a precut size of $1.5 \times 11 \mathrm{~cm}$ (Varian, Inc., and Auburn Biostrips). The solvent mixture was poured into the vial to a depth of about $0.5 \mathrm{~cm}$ at the bottom. A small drop $(\sim 10 \mu \mathrm{L})$ of the reconstituted ${ }^{99 \mathrm{~m}} \mathrm{Tc}$-tetrofosmin sample was spotted using the $1-\mathrm{mL}$ syringe with 25 -gauge needle at $1.0 \mathrm{~cm}$ above one end of a strip, and an ink mark was spotted at $1 \mathrm{~cm}$ below the other end. The strip was then placed in the cylindric vial so that the sample spot remained above the solvent. When the solvent reached the ink spot, the strip was removed and air dried to determine the distribution of the 3 components along the strip.
As the solvent ascends the strip, the 3 components migrate to different distances on the strip depending on their solubility in the solvent and adsorption on the solid phase. Each component is characterized by a relative front $\left(R_{f}\right)$ value, which is defined as the ratio of distance traveled by the component to the distance traveled by the solvent front from the sample spot (4). After developing the chromatogram, we cut the strip into 8 equal segments between the sample spot and the solvent to establish these $R_{f}$ values. The activity in each segment was measured in a dose calibrator and plotted in a histogram. A typical chromatogram obtained from a single ITLC method on a ${ }^{99 \mathrm{~m} T c-t e t r o f o s-}$ min sample using SA and SG strips is shown in Figure 1. The distribution of the activities indicates the bound ${ }^{99 \mathrm{~m}} \mathrm{Tc}$ in the middle, free ${ }^{99 \mathrm{~m}} \mathrm{Tc}$ at the solvent front, and hydrolyzed ${ }^{99 \mathrm{~m}} \mathrm{Tc}$ at the origin, providing the $R_{f}$ values of the 3 components. Once the average of these values was established from several initial experiments, in subsequent experiments we simply cut the strips around the peaks of the 3 components for convenience and determined the activities of the 3 segments. The cut positions were marked at 1.5 and $7.5 \mathrm{~cm}$ from the spot (or 2.5 and $8.5 \mathrm{~cm}$ from the bottom) as shown in Figure 2A. The bottom segment contained hydrolyzed ${ }^{99 \mathrm{~m}} \mathrm{Tc}$, and the upper segment free ${ }^{99 \mathrm{~m}} \mathrm{Tc}$, whereas the middle segment, which had the highest activity, represented

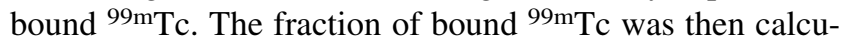
lated as

$$
\% \text { bound }=\frac{\text { Activity of middle segment }}{\text { Activity of all } 3 \text { segments }} .
$$

For comparison, identical chromatographic experiments were performed following the method recommended by the manufacturer in the package insert of ${ }^{99 \mathrm{~m}} \mathrm{Tc}$-tetrofosmin, which uses the solvent mixture of 35:65 acetone and dichloromethane and an SG strip as the solid phase (Table
FIGURE 1. Distribution of $99 \mathrm{mTc}$ components in ${ }^{99 m}$ Tc-tetrofosmin preparation on SA and SG strips.

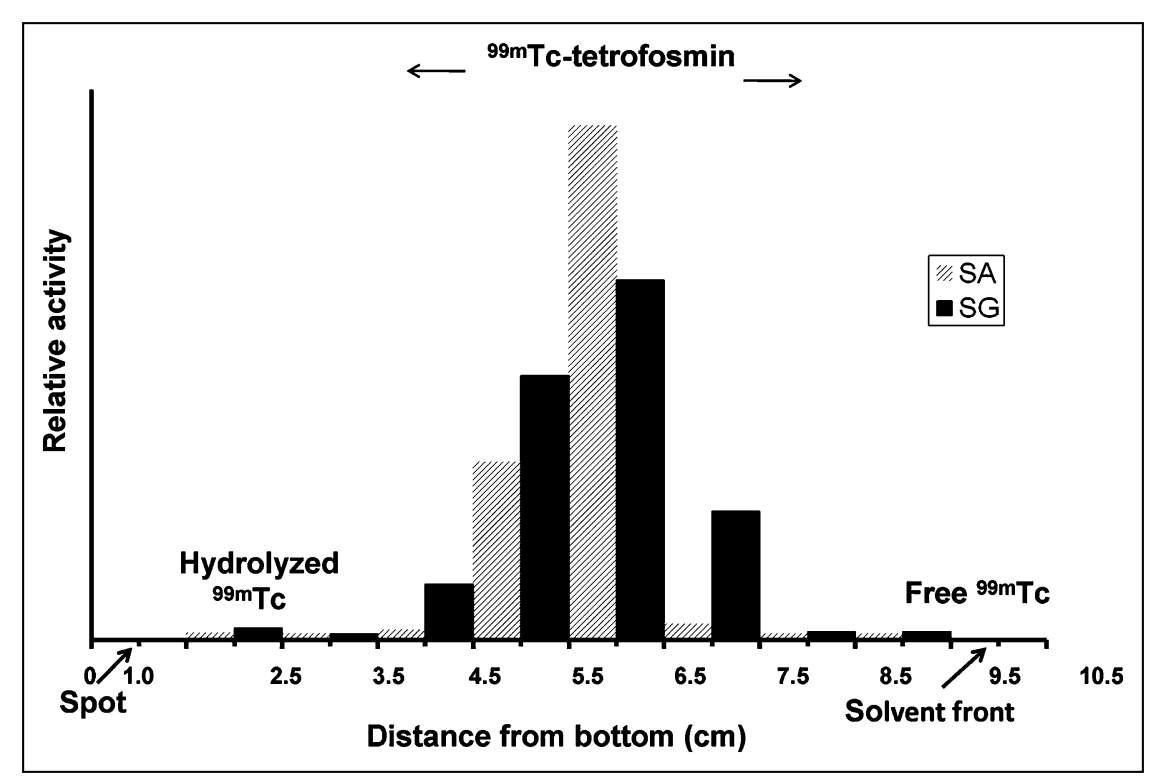




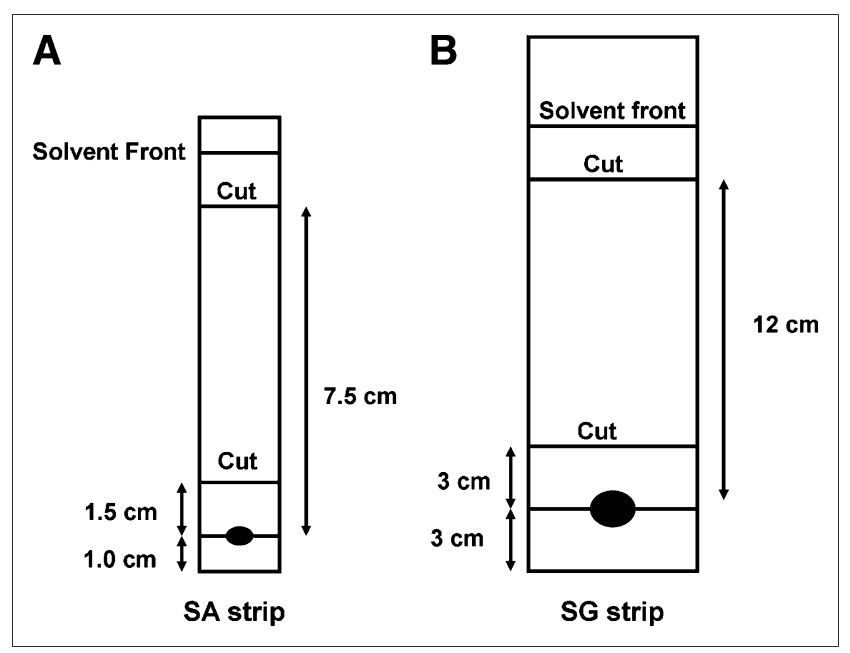

FIGURE 2. Cutting marks for the three ${ }^{99 m}$ Tc components on SA (A) and SG (B) strips.

1). The recommended size of the strip was $2 \times 20 \mathrm{~cm}$, which is longer than the current SA strip used. The cut marks, which are different from those in the SA strips, are shown in Figure 2B for comparison.

\section{RESULTS}

ITLC was performed on 26 freshly prepared samples of ${ }^{99 \mathrm{~m} T c-t e t r o f o s m i n}$, and the results for both SG and SA strips are presented in Figure 3 The figure shows a comparison of percentage-bound ${ }^{99 \mathrm{~m}} \mathrm{Tc}$ (radiochemical purity) in each individual preparation of ${ }^{99 \mathrm{~m}} \mathrm{Tc}$-tetrofosmin obtained by the manufacturer's method and by our alternative method. The radiochemical purity is more than $90 \%$ by either method, and the average value is $96.5 \% \pm 1.13 \%$ for the SA strip and $96.3 \% \pm 1.07 \%$ for the SG strip. There is no significant difference between the 2 values, which agree well within $1 \mathrm{SD}$.

Although the $R_{f}$ value of ${ }^{99 \mathrm{~m}} \mathrm{Tc}$-tetrofosmin with the SG strip as seen in Figure 1 seems to be slightly higher than that with the SA strip, both values overlap in the range of 0.3-0.8. On this basis, we cut the 3 segments on the SA strip at the marks shown in Figure 2B, with the middle segment $(2.5-8.5 \mathrm{~cm}$ from the bottom) representing the

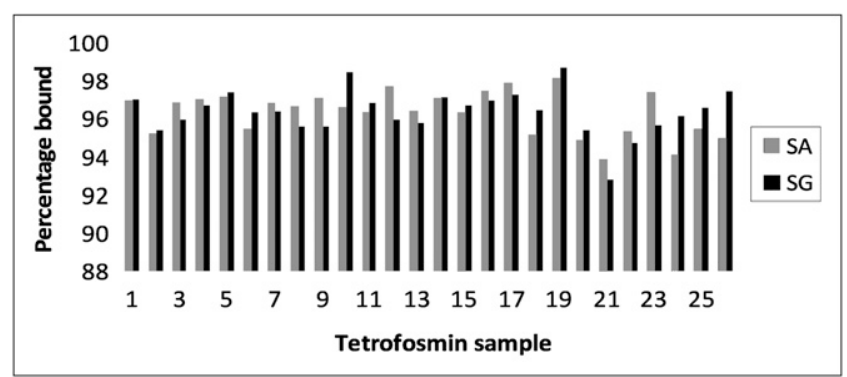

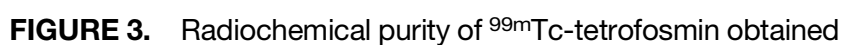
by $S A$ and SG strips in 26 reconstituted samples. bound fraction. The average $R_{f}$ values of free, hydrolyzed, and bound ${ }^{99 \mathrm{~m}} \mathrm{Tc}$ obtained are in Table 2 and essentially show no difference between the 2 methods.

\section{DISCUSSION}

${ }^{99 m} \mathrm{Tc}$-tetrofosmin is used in humans for the assessment of myocardial perfusion to distinguish between ischemia and infarction in the heart (5). The high radiochemical purity $(>90 \%)$ of the radiopharmaceutical is required for better diagnostic detection of myocardial defects and to avoid unnecessary adverse effects and radiation exposure to patients. For convenience and to keep the procedure brief, the ITLC method is commonly used to separate and estimate the different components of a ${ }^{99 \mathrm{~m} T c-t e t r o f o s m i n ~ p r e p-~}$ aration. After several trial experiments, the SA strip was fortuitously found to offer an excellent alternative to the manufacturer's SG strip for the ITLC analysis of ${ }^{99 m} \mathrm{Tc}-$ tetrofosmin preparations using a mixture of acetone and dichloromethane (with a reverse volume ratio of 65:35) as the solvent. The average radiochemical purity of ${ }^{99 \mathrm{~m} T c-}$ tetrofosmin obtained by our method and the manufacturer's method is above $96 \%$ and compares well with that of McKay et al. (2) and Eggert et al. (3). However, both reports used different solid phases and solvents in the ITLC method.

The ITLC method described here is quite short, requiring only 3-4 min for the entire procedure. Easy commercial availability of the SA strip and solvents makes the method more acceptable. A caveat is that acetone and dichloromethane are volatile and may be harmful. The adverse effects depend on the extent of exposure and range from such complaints as headache and dizziness at low exposure to liver damage and cancer at high exposure. It is recommended that these chemicals be handled with caution and preferably in a well-ventilated area.

\section{CONCLUSION}

In the absence of SG strips, SA strips are an appropriate substitute as the solid phase along with a 65:35 acetone: dichloromethane mixture as the solvent for assessing the radiochemical purity of ${ }^{99 \mathrm{~m}} \mathrm{Tc}$-tetrofosmin. This alternative method will serve well for all commercial nuclear pharmacies, as well as for individual institutions that prepare ${ }^{99 m}$ Tc-tetrofosmin daily.

TABLE 2

Average $R_{f}$ Values of Different ${ }^{99 m T c}$ Components in 99mTc-Tetrofosmin Preparation

\begin{tabular}{lll}
\hline \multicolumn{1}{c}{ Component } & SG strip & SA strip \\
\hline${ }^{99 m}$ Tc, free & $0.9-1.0$ & $0.9-1.0$ \\
99mTc, hydrolyzed & $0.0-0.2$ & $0.0-0.2$ \\
99mTc-tetrofosmin & $0.3-0.8$ & $0.3-0.8$ \\
\hline
\end{tabular}




\section{ACKNOWLEDGMENT}

This work was presented in part at the annual meeting of the Society of Nuclear Medicine in Salt Lake City in 2010.

\section{REFERENCES}

1. Myoview [package insert]. Arlington Heights, IL: GE Healthcare; August 2006.
2. McKay BF, Zimmer AM, Spies SM. Rapid miniaturized chromatography for technetium-99m-tetrofosmin. J Nucl Med Technol. 1997;25:52-54.

3. Eggert LA, Dick MD, Mahoney DW, Olson JP, Werner GL, Hung JC. A rapid

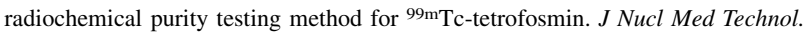
2010;38:81-84.

4. Saha GB. Quality control of radiopharmaceuticals. In: Fundamentals of Nuclear Pharmacy. 6th ed. New York, NY: Springer; 2010:157.

5. Rigo P, Leclercq P, Itti R. Technetium-99m-tetrofosmin myocardial imaging: a comparison with thallium-201 and angiography. J Nucl Med. 1994;35:587-593. 